\title{
UNA PROPUESTA EXPLORATORIA DEL PERFIL PROFESIONAL EN TURISMO DESDE LIMÓN, COSTA RICA (2018)
}

Revista Trama

Volumen 8 , número 2

Julio - Diciembre 2019

Páginas 146-190

ISSN: 1659-343X

https://revistas.tec.ac.cr/trama
An exploratory proposal of the professional profile in tourism from Limón, Costa Rica (2018)

Cherry Espinoza Vargas $^{1}$
Fabián Alvarado Redondo ${ }^{2}$
Katherine Castro Zúñiga
Ignacio Solano Porras
${ }^{4}$
Yolanda Zúñiga Batista

Fecha de recepción: 18 de octubre de 2018 Fecha de aprobación: 27 de noviembre de 2019

Espinoza, C.; Alvarado, F.; Castro, K.; Solano, I. y Zúñiga, Y. (2019). Una propuesta exploratoria del perfil profesional en turismo desde Limón, Costa Rica. Trama, Revista de ciencias sociales y humanidades, Volumen 8 ,

(2), págs. 146-190.

DOI: https://doi.org/10.18845/tramarcsh.v8i2.4946

1. Bachiller en Gestión de Turismo Sostenible. Instituto Tecnológico de Costa Rica. Cartago, Costa Rica. Correo electrónico: cherryespinoza03@gmail.com

2. Bachiller en Gestión de Turismo Sostenible. Instituto Tecnológico de Costa Rica. Cartago, Costa Rica. Correo electrónico: f.abst57@gmail.com

3. Bachiller en Gestión de Turismo Sostenible. Instituto Tecnológico de Costa Rica. Cartago, Costa Rica. Correo electrónico: kathyc1308@gmail.com

4. Bachiller en Gestión de Turismo Sostenible. Instituto Tecnológico de Costa Rica. Cartago, Costa Rica. Correo electrónico: spignacio89@gmail.com

5. Bachiller en Gestión de Turismo Sostenible. Instituto Tecnológico de Costa Rica. Cartago, Costa Rica. Correo electrónico: yozubafy@hotmail.com 


\section{Resumen}

La siguiente investigación surge a partir de la falta de estudios actuales realizados en Costa Rica y propiamente de la provincia de Limón, que refiere a la preparación de profesionales para el sector turismo. El objetivo de la siguiente investigación da respuesta a cuál es el perfil profesional que se requiere para responder a las necesidades actuales y futuras del sector turismo, donde se brindarán variables, se identificarán conocimientos, habilidades y actitudes con el fin de formular el perfil profesional acorde para la provincia.

Para fundamentar dicho trabajo se procede a la extracción y revisión bibliográfica, además de un mapeo y un método que definirá conceptos y teorías de turismo, perfil profesional, dando a la investigación un enfoque cualitativo y una investigación etnográfica. El trabajo presenta aportes de diversas áreas profesionales, de grado académico, educativo, sector de gobierno local, sector empresarial, egresados de la carrera de Gestión de Turismo Sostenible, que dieron importantes y diferentes perspectivas, para brindar una propuesta del perfil profesional de Turismo para el distrito Central de Limón.

Palabras clave: perfil profesional, gestión, turismo, ocio, recreación, Limón.

\section{Abstract}

The following research arises from the lack of current studies conducted in Costa Rica and the province of Limon itself, which refers to the preparation of professionals for the tourism sector. The objective of the following investigation gives answer to which is the professional profile that is required to respond to the current and future necessities of the tourism sector, where variables will be offered, knowledge, abilities and attitudes will be identified in order to formulate the professional profile according to the province.

In order to base this work, we proceed to the extraction and bibliographic revision, besides a mapping and a method that will define concepts and theories of tourism, professional profile, giving to the investigation a qualitative approach and an ethnographic investigation. The work presents contributions from various professional areas, academic degree, education, local government sector, business sector, graduates of the Sustainable Tourism Management career, which gave important and different perspectives, to provide a proposal for the professional profile of Tourism for the Central district of Limon.

Keywords: professional profile, management, tourism, Limón. 


\section{INTRODUCCIÓN}

El objetivo de la siguiente investigación es brindar aportes para la construcción de un perfil profesional en turismo desde la universidad pública en la provincia de Limón. Esto con el propósito de dar a conocer las capacidades y competencias que identifican la formación del profesional en turismo. Este trabajo se centra en establecer las necesidades actuales del sector turístico en el distrito central del cantón de Limón.

La construcción de un perfil profesional en turismo reviste de gran importancia en especial cuando se observa el creciente desempleo en el caso de egresados de carreras dirigidas al sector turismo y a la constante contratación de personal no capacitado, tal como lo demuestran las encuestas de seguimiento a graduados universitarios que realiza el Consejo Nacional de Rectores (CONARE), como se citó en Estado de la Nación (2015) el cual afirma que:

"el desempleo entre los profesionales es bajo (menos de la mitad del promedio nacional), aunque hay disciplinas que deben revisarse, pues tienen condiciones desfavorables de inserción laboral: subempleo por insuficiencia de horas o trabajos poco relacionados con la carrera estudiada" (p. 103).

Frente a los diversos procesos de innovación y cambio que se proyectan para la provincia de Limón mediante el desarrollo de diferentes proyectos tanto públicos como privados, es requerido pensar en la formación académica necesaria que deben tener las y los profesionales que trabajarán en las diferentes áreas tanto del campo académico del turismo, como de distintos sectores vinculados a la actividad de recreación y ocio.

Dicha formación requiere ser considerada, centrada y orientada hacia el desarrollo de un perfil profesional que logre describir de forma clara, el conjunto de capacidades y competencias que identifican la formación de un especialista en el campo del turismo, con el fin de que éste logre encarar de forma responsable las funciones y tareas de esta profesión en el contexto de una provincia situada en uno de los centros neurálgicos del turismo en el caribe costarricense, centroamericano y mundial. 
De acuerdo a esta realidad, la presente investigación tiene como objetivo dar aportes en la formulación de un perfil profesional en turismo adecuado a la provincia de Limón, en Costa Rica.

La trascendencia que tiene este problema de investigación para el campo de la Gestión del Turismo Sostenible radica en que no existe un estudio sobre el perfil profesional en el sector turismo desde la realidad de esa provincia costera costarricense. 


\section{ANTECEDENTES}

Este apartado corresponde a los antecedentes encontrados a nivel de Costa Rica, los mismos refieren a investigaciones enfocadas en temas como: teorías de desarrollo y la falta de planeación que presenta el sector turismo. Para ello se divide la información en tesis, artículos y una investigación no publicada.

Orozco y Núñez (2013) refieren que el objetivo de su investigación fue proporcionar elementos teóricos que nos permitan entender los problemas del desarrollo y generar reflexiones para comprender el rumbo que han tomado muchos destinos turísticos.

La metodología de esta investigación se centra en el análisis bibliográfico de diversos enfoques sobre el desarrollo: la revisión fue sobre las teorías del desarrollo y teorías del desarrollo local. Como resultado en este trabajo se obtienen diversos elementos que permiten comprender y recomendar acciones en pro de fomentar un desarrollo turístico equilibrado, entre ellos destaca el impulsar un desarrollo integral e incluyente en lo que refiere a las condiciones de vida de las poblaciones locales, concluyendo con una invitación a ofrecer y promover un mejor servicio, una cultura turística valorando la importancia del turismo y la conservación de su patrimonio.

Por su parte Carballo (2013) presenta como principal objetivo mostrar los resultados de la investigación del Proyecto Centros Históricos del Turismo, realizado por la Universidad de Costa Rica (UCR).

La metodología utilizada fue mediante el uso de estadísticas, selección y construcción del instrumento de recolección de información y análisis con el fin de recabar información del Censo que se desarrolló en el Barrio Pacuare en el año 2011. Entre los resultados obtenidos con dicha investigación se destaca un porcentaje importante en cuanto a la tipología laboral teniendo el sector público y formal la dinámica más constante de trabajo del Pacuare. Además, se refleja en los datos que el Turismo es la actividad que alberga la mayor cantidad de personas trabajadoras procedentes de la misma zona, siendo este una actividad económica importante para muchas personas, a pesar de ello, algunos grupos no son observables por medio del censo, por lo que 
es válido recomendar otra investigación con mayor profundidad que complemente este estudio.

Según Guzmán, Fernández, Villalobos, Monreal, Rivero y Blanco (2015), fundamentan como objetivo elaborar una propuesta de oferta curricular, acorde a las necesidades como respuesta al desarrollo del país desde el punto de vista de la Ingeniería Agroindustrial, para lo anterior fue necesario conocer las necesidades de contar con profesionales en las regiones Huetar Norte, Caribe y Chorotega.

La metodología empleada se desarrolló mediante diferentes pasos, dando inicio con un estudio de mercado, seguido por la formulación de un perfil profesional, una extensa revisión bibliográfica y finalmente la creación de una comisión de diseño curricular. En conclusión, los resultados de la investigación arrojan que el perfil profesional adecuado debe dar respuesta a una formación interdisciplinaria e integral, capaz de buscar alternativas de producción y con competencias para la investigación y el desarrollo de procesos eficientes y de alto valor agregado.

Jensen (2004) manifiesta que el objetivo de la investigación fue realizar un diagnóstico de las necesidades actuales de capacitación de las empresas y organizaciones afiliadas a la Cámara Nacional de Turismo de Costa Rica, con el fin de recabar información pertinente para la creación de un programa de capacitación y desarrollo.

La metodología empleada para el desarrollo del proyecto fue de base bibliográfica, además fue preciso la observación de documentales y la realización de entrevistas a través de resultados descriptivos. En cuanto al resultado obtenido se destaca que los temas de capacitación más necesarios en un eventual programa por orden de importancia son: el servicio al cliente, el mercadeo, las relaciones interpersonales, el liderazgo, el planeamiento estratégico y la protección al medio ambiente.

Esta es una investigación no publicada, con la finalidad de evaluar el mercado turístico. 
Lao (2012) expresa que el objetivo de su investigación fue desarrollar un perfil académico profesional curricular, con la intención de desarrollar una carrera con demanda económica y social.

La metodología desarrollada fue mediante entrevistas, revisión bibliográfica de fuentes secundarias y bases de datos universitarios, así como el análisis de variables y factores determinantes sobre el perfil académico / ocupacional del egresado en turismo. Como resultados se puede concluir que en dichas entrevistas los porcentajes en las estadísticas eran constantes, observándose como una carrera muy necesaria, parte por el hecho de que es importante innovar, además de desarrollar la sostenibilidad y cuidar el ambiente.

En conclusión, los antecedentes utilizados han sido de mucha utilidad e importancia, para esclarecer y comprender el objetivo que tiene esta investigación con respecto al perfil profesional del sector turismo que se pretende diseñar para el distrito Central de la provincia de Limón. 


\section{TURISMO EN COSTA RICA Y LIMÓN}

Según el Programa Estado de la Nación (2019), el turismo es un eje fundamental en la estructura productiva de Costa Rica. Esta actividad productiva de carácter territorial y sectorial y con un vínculo internacional está directamente asociado con los recursos naturales y es una importante fuente de encadenamientos productivos. No obstante, el turismo receptor (el de los extranjeros no residentes) tiene bajo efecto multiplicador del gasto en turismo, o efecto de "derrame" en la economía costarricense:

En efecto, Meneses et al. (2019) determinaron que la demanda del turismo receptor estadounidense y centroamericano redujo la participación de sectores con algún tipo de encadenamiento (claves, estratégicos e impulsores) y aumento la demanda de actividades poco relacionadas con el resto de la economía (independientes; grafico 3.17). Específicamente, entre 2012 y 2016 en ambos casos se registró un aumento en los servicios de atención de la salud humana, refinación de petróleo y enseñanza, los cuales generan pocos encadenamientos productivos (independientes), al tiempo que se redujo el peso relativo del transporte por vía marítima, aérea y de carga por carretera (estratégico), los servicios de comida y bebidas (clave) y el alojamiento (impulsor). Sumado a lo anterior, llama la atención que también disminuyo el peso relativo de la demanda estadounidense por servicios de agencias de viajes y operadores turísticos (impulsores), los cuales podrían estar siendo sustituidos por servicios digitales ofrecidos desde ese país (Programa Estado de la Nación, 2019: 142).

El más reciente índice turístico determinó que Costa Rica es el segundo país donde el turismo tiene un mayor peso sobre el producto interno bruto (PIB) (La Nación, 2010). Así, se indica que el 7,1 \% de todo lo que se produce anualmente en ese país centroamericano proviene de la actividad de recreación y ocio, convirtiéndose en uno de los mayores generadores de divisas del país.

Según sea su motivación, el turista puede tener diferentes necesidades de viaje, como tener contacto con la naturaleza; estar en equilibrio con cuerpo, mente y espiritu; o hasta buscar nuevos conocimientos y experiencias. 
Según el Instituto Costarricense de Turismo (ITC) (2018), el turista visita el pais por las siguientes motivaciones:

Tabla 1. Estimación de la cantidad de turistas según motivo principal de la visita a Costa Rica 2012-2018.

\begin{tabular}{|c|c|c|c|c|c|c|c|c|c|c|c|c|c|c|}
\hline \multirow{2}{*}{ Motivo principal de la visita ${ }^{1}$} & \multicolumn{2}{|l|}{2012} & \multicolumn{2}{|l|}{2013} & \multicolumn{2}{|l|}{2014} & \multicolumn{2}{|l|}{2015} & \multicolumn{2}{|l|}{2016} & \multicolumn{2}{|l|}{2017} & \multicolumn{2}{|l|}{2018} \\
\hline & Turistas & $\%$ & Turistas & $\%$ & Turistas & $\%$ & Turistas & $\%$ & Turistas & $\%$ & Turistas & $\%$ & Turistas & $\%$ \\
\hline Total & 2343213 & 100,0 & 2427941 & 100,0 & 2526817 & 100,0 & 2660257 & 100,0 & 2925128 & 100,0 & 2959869 & 100,0 & 3016667 & 100,0 \\
\hline Motivos personales & 2036726 & 86,9 & 2140556 & 88,2 & 2179813 & 86,3 & 2241180 & 84,2 & 2630514 & 89,9 & 2715317 & 91,7 & 2731277 & 90,5 \\
\hline Vacaciones, recreo y ocio & 1688562 & 72,1 & 1819719 & 74,9 & 1903744 & 75,3 & 1939288 & 72,9 & 2168225 & 74,1 & 2288691 & 77,3 & 2237692 & 74,2 \\
\hline Visitas a familiares y amigos & 246549 & 10,5 & 238102 & 9,8 & 223725 & 8,9 & 244220 & 9,2 & 363170 & 12,4 & 294540 & 10,0 & 317799 & 10,5 \\
\hline Educación y formación & 39493 & 1,7 & 28405 & 1,2 & 20261 & 0,8 & 19154 & 0,7 & 36219 & 1,2 & 40824 & 1,4 & 68860 & 2,3 \\
\hline Salud y atención médica & 13287 & 0,6 & 7904 & 0,3 & 3941 & 0,2 & 9774 & 0,4 & 13131 & 0,4 & 18913 & 0,6 & 15901 & 0,5 \\
\hline Otros motivos personales & 48835 & 2,1 & 46425 & 1,9 & 28142 & 1,1 & 28745 & 1,1 & 49768 & 1,7 & 72349 & 2,4 & 91025 & 3,0 \\
\hline Negocios y motivos profesionales & 306487 & 13,1 & 287385 & 11,8 & 347004 & 13,7 & 419077 & 15,8 & 294614 & 10,1 & 244552 & 8,3 & 285390 & 9,5 \\
\hline Conferencias o congresos & 24035 & 1,0 & 38645 & 1,6 & 74019 & 2,9 & 31164 & 1,2 & 32424 & 1,1 & 25516 & 0,9 & 29382 & 1,0 \\
\hline $\begin{array}{l}\text { Otros motivos profesionales } \\
\text { (Reuniones, ferias o exposiciones) }\end{array}$ & 282452 & 12,1 & 248740 & 10,2 & 272986 & 10,8 & 387913 & 14,6 & 262190 & 9,0 & 219036 & 7,4 & 256008 & 8,5 \\
\hline
\end{tabular}

Nota:1/ Estimación utilizando la distribución del motivo principal de la visita vía aérea y la Información de las llegadas internacionales proporcionada por la Dirección General de Migración y Extranjería.

Fuente: ICT (2018), Encuestas de no residentes en los aeropuertos internacionales.

Según el cuadro anterior, cabe destacar que mayoría de los turistas que visitan Costa Rica en el año 2018, el 74,2\% de los turistas indicaron que su motivo principal de viaje era por vacaciones, recreo u ocio; el 10,5\% por visita a familiares y; el 8,5\% por negocios y motivos profesionales.

Una de las provincias de Costa Rica más privilegiadas con la llegada de turistas tanto nacional como internacional es la provincia de Limón. Esta provincia, situada en la región Huetar Caribe, tiene una extensión territorial aproximada de 9,188.52 km2 (918.852 ha), lo cual representa el $17,98 \%$ del territorio nacional. Esta región destaca por la mayor proporción de su actividad económica concentrada en monocultivos de exportación, especialmente en el cultivo de piña y banano (Programa Estado de la Nación, 2019). Cuenta con 2 complejos portuarios de suma importancia para el país como es la terminal Hernán Garrón Salazar, conocido popularmente como "Puerto Limón"; y la terminal Gastón Kogan Kogan, nombrado como "Muelle Moin". 
En estos complejos portuarios es donde atraca gran cantidad de cruceros que visitan la provincia. De este modo, las divisas generadas por las actividades turísticas impactan tanto en el desarrollo socioeconómico del país, como en la generación de fuentes de empleo y el ingreso económico de numerosas familias de la región.

No obstante, el Informe en Desarrollo Humano Sostenible (2019: 145) señala algunos problemas cruciales para la economía de la provincia de limón:

la información de las encuestas que realiza el ICT se puede identificar el margen de acción para ampliar el contacto de estos turistas con las comunidades, mediante la mejora de la oferta turística local. Según la encuesta de cruceros para la temporada 2017-2018, en los puertos de Limón y Puntarenas más de la mitad de los cruceristas no compra tours locales, no visita por cuenta propia otros lugares del país, tiene una estadía promedio en tierra de no más de tres horas y las principales razones de insatisfacción de su visita son suciedad, pobreza, infraestructura vial, transporte y una oferta limitada de tiendas, actividades y restaurantes (ICT 2019; citado por Programa Estado de la Nación, 2019: 145).

Sin embargo, no todos los limonenses tienen las mismas ventajas o las mismas oportunidades. Para nadie es un secreto que Limón ha sido una de las provincias con mayores problemas sociales y económicos de Costa Rica. Históricamente, desde el enclave bananero de la United Fruit Company, la construcción del ferrocarril, hasta la concesión de puertos como lo es APMTerminals, la riqueza y los capitales producidos localmente son transferidos mayormente a través de las redes y las sedes de las corporaciones transnacionales radicadas en los países centrales, sin que sean cumplidas las promesas del desarrollo de las fuerzas productivas del capitalismo en general y del turismo de masas en particular. En estas condiciones, la provincia de Limón se somete a la lógica capitalista del Estado y de las grandes corporaciones transnacionales que se apoderan, explotan y extraen las riquezas, dejando a los habitantes de la provincia con las"migajas" de la riqueza y en condiciones de pobreza y desigualdad generados por un modelo de desarrollo desigual y asimétrico. Ello se evidencia en las profundas problemáticas de desempleo, criminalidad y 
narcotráfico, que ha dado tan mala reputación a la zona. Ante esto, los impulsos de sectores públicos (ICT, SINAC, etc.) y privados (como las cámaras empresariales) de la estructura productiva del turismo tienen enormes desafíos:

Dado este contexto, Costa Rica tiene tres grandes desafíos para el diseño de su estrategia en este ámbito: reorientar la demanda del turismo estadounidense hacia actividades con mayores encadenamientos productivos; fomentar las visitas de ciudadanos europeos, que tienen un gasto promedio alto y demandan productos locales, y aumentar el gasto promedio del turismo interno. Además se debe mejorar la infraestructura vial y la seguridad para los visitantes, factores decisivos del crecimiento del sector (Programa Estado de la Nación, 2019: 146).

De tal manera, el Programa Estado de la Nación (2019: 146) evidencia disparidades en los beneficios del turismo entre trabajadores y capital:

Sin embargo, no necesariamente esas actividades tienen una alta capacidad de encadenar la economía. La relación entre el tipo de encadenamiento y el nivel de apropiación de las ganancias por parte de los trabajadores, para cada una de las actividades turísticas según el tamaño de la producción. Allí se puede observar, por ejemplo, que los servicios de salud que consumen los turistas tienen baja capacidad de generar encadenamientos, pero también elevados niveles de apropiación. En cambio, el sector transporte por vía aérea y marítima, que tiene alta capacidad de empuje de la economía con encadenamientos de tipo estratégico, registra un nivel bajo en la apropiación de ganancias. También se identifican actividades que tienen altos niveles de encadenamientos y una distribución equitativa entre trabajadores y capital, tales como: los servicios de comida y bebidas, el comercio, las agencias de viajes y el alojamiento, las cuales, en conjunto, representan un 34\% del PIB turístico. Así pues, las políticas de fomento turístico deben considerar que el impulso a sectores con alto nivel de encadenamiento no 
necesariamente genera altos beneficios para los trabajadores (Programa Estado de la Nación, 2019: 146).

Limón, a pesar de ser una provincia tan invisibilizada (Chaverri, 2018), cuenta con una población multiétnica e intercultural, así como una rica biodiversidad que, en su conjunto, potencian la importancia turística en el caribe de ese país centroamericano.

Un breve inventario de esta riqueza se evidencia, entre otras manifestaciones, en la gastronomía a base de coco; en las manifestaciones únicas de baile y música calypso; en los carnavales de vibrantes comparsas y bailarinas/es de coloridos trajes; en el inglés criollo limonense. Esta producción cultural diferencia a Limón de las demás provincias del país.

Una de las celebraciones más emblemáticas de la provincia de Limón es el carnaval. Esta celebración se inició a partir del año 1949 e incluía disfraces y comparsas. Arley (2012) establece que el carnaval es un festejo cíclico; "un año sin carnaval es realmente un año de ayuno y abstinencia, de sacrificio". El carnaval no resuelve crisis, pero sí abre un espacio para la libertad, para que la comunidad se encuentre con sus tradiciones; es la oportunidad para que visitantes disfruten de un evento culturalmente único en el país.

El caribe norte y el caribe sur resguardan maravillas naturales; son territorios privilegiados por su posición geográfica. Gracias a su clima tropical-húmedo ofrece una compleja biodiversidad.

En el caribe costarricense existen atractivos turísticos como son los parques Nacionales y áreas protegidas, tal como es el Parque Nacional Gandoca Manzanillo que conserva y protege diferentes ecosistemas que incluyen una atractiva playa de arena amarilla, el arrecife de coral, y sus humedales. Algunas actividades que el visitante puede realizar en este sitio son el buceo, el montar en bicicleta, conocer el pueblo y su cultura, disfrutar del sol, el mar y la playa.

Otro parque nacional de Limón es Cahuita. Este parque protege uno de los arrecifes coralinos más desarrollados del caribe y con una belleza escénica incomparable, playa de arena blanca, senderos entre el 
bosque y es uno de los lugares favoritos para quienes les gusta practicar deportes como el volleyball y el surf.

El parque Nacional Tortuguero, en el caribe norte, es una de las zonas más ricas en cuanto a flora y fauna. Posee canales navegables y ha sido uno de los lugares más importantes para el desove de tortugas verdes. En las aguas de este parque habita el manatí, un mamífero que se encuentra en peligro de extinción, su playa no es recomendada para los bañistas.

Limón también posee una oferta turística en los territorios indígenas bribri y cabécar. Al respecto, destacan distintas iniciativas turísticas en las localidades de Yorkín, Shuap y Amubre. Estas han contado con el acompañamiento y la gestión del turismo sostenible desde la Escuela de Ciencias Sociales del Instituto Tecnológico de Costa Rica y; ella está diseñada para turistas motivados en experimentar la cultura de manera vivencial, acercarse al modo de vida, la cultura, el saber ancestral, la historia de sus rebeliones, el mundo natural y espiritual de estos pueblos. 


\section{MARCO TEÓRICO}

Para Tamayo (2012), la elaboración del marco teórico consiste en presentar un conjunto de postulados sustentados por diversos autores, es decir, diversas maneras de analizar un problema. Para esta investigación se ha planteado como problema: ¿Cuál es el perfil profesional que requiere el sector turismo en el distrito central del cantón de Limón?

Siguiendo a Hernández et al (2014), el marco teórico de esta investigación se denomina índice "vertebrado" el cual refiere al desarrollo en general, que busca definir los conceptos o teorías sobre los cuales se va estructurar el marco teórico de la investigación. Se utilizó este método ya que el mismo permite establecer líneas de relación temática que permitan comprender la complejidad y la red conceptual sobre la que se fundamenta la investigación.

Figura 1. Marco teórico por medio de modelo de índice vertebrado.

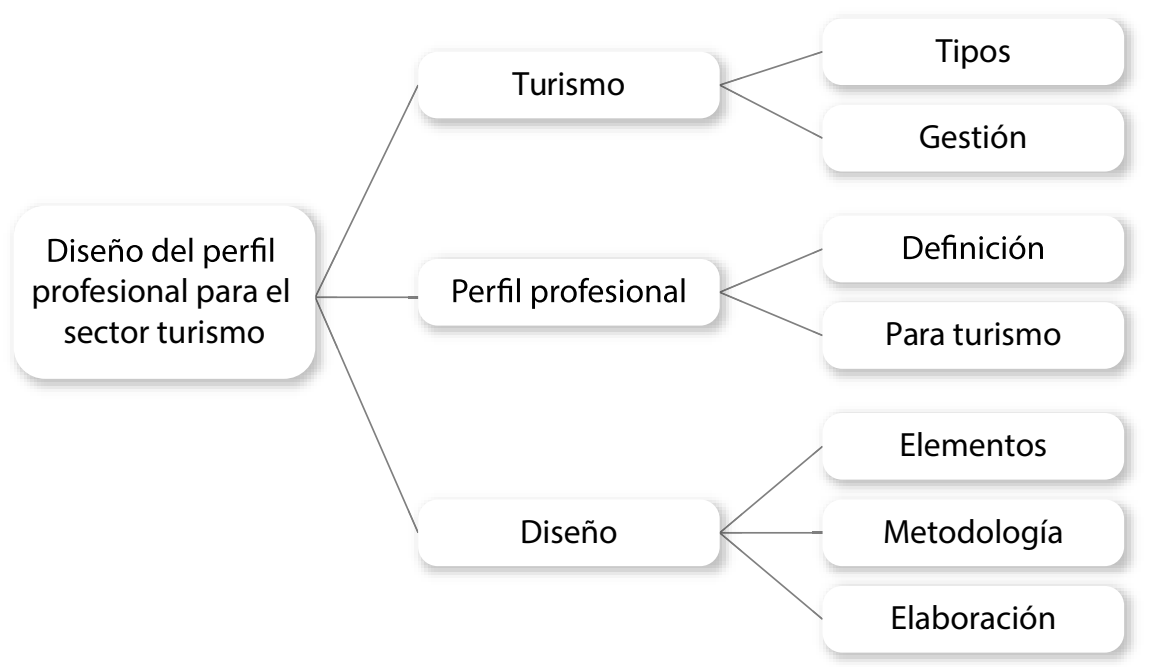

Fuente: elaboración propia (2017) a partir de Herández (2014, p. 79).

A partir de la figura se puede comprender lo siguiente: 
La columna vertebral del marco teórico está conformada por:

\section{Turismo}

Dentro de la estructura de esta investigación se comprende el turismo como un conjunto de actividades multidisciplinarias que transforman el espacio geográfico en el que se encuentra, con la finalidad de generar una oferta amplia acorde a las necesidades del sector.

Según Guerrero y Ramos (2014), el turismo se entiende como una "actividad humana que conlleva el deseo de satisfacer diversas motivaciones del turista, las cuales son variadas y sobre todo de carácter personal (...) Lo que conlleva que el turismo sea diversificado, específico, social, económico y humano" (p. 32-33).

En términos más amplios, el turismo es"un hecho social, económico, espacial, medioambiental y culturalmente responsable, de cientificidad multidisciplinaria, desarrollado sistémicamente, bajo los principios de la sostenibilidad y la nueva economía digital" (Jiménez, 2013, p. 6)

Por lo tanto, tomando en cuenta lo mencionado por Guerrero y Ramos (2014) y Jiménez (2013), el turismo es una manifestación humana, que conlleva un proceso integral que va desde lo social hasta lo cultural, que implica un conjunto de actividades diversas dentro de un contexto geográfico particular que se va desarrollando a lo largo de un proceso histórico.

Conlleva necesariamente a valorar que dicha actividad o actividades impactan a las personas desde diversos ámbitos, uno de los impactos más visibles es la generación de diversas fuentes de ingresos económicos, por medio de la generación de empleo, la cual se asocia con las motivaciones que tienen los turistas para viajar. Algunas de estas motivaciones pueden ser: ocio, recreo, vacaciones, salud, religión, negocios y motivos profesionales. 
En este trabajo el turismo el primer núcleo del cual se desprenden las líneas temáticas de tipos y gestión, como se ejemplifica en la siguiente figura:

Figura 1. Marco teórico por medio de modelo de índice vertebrado.

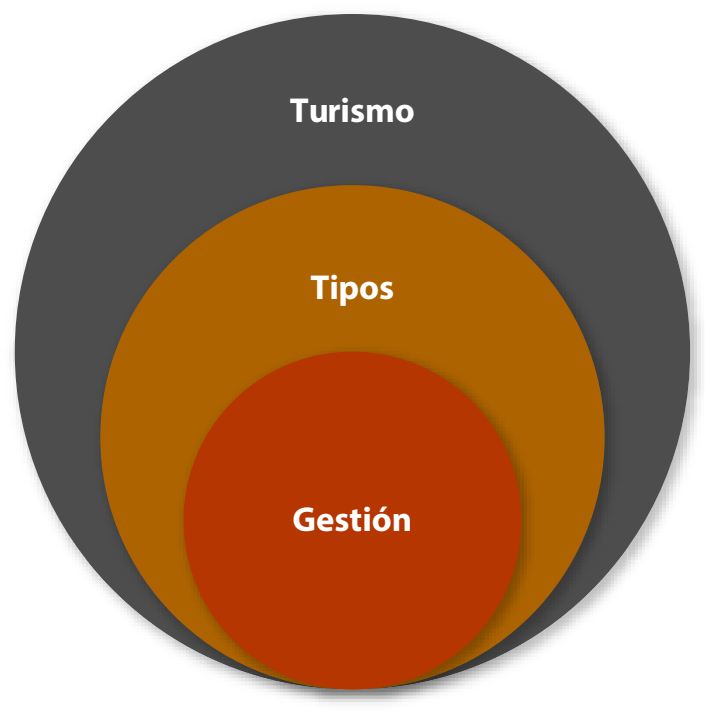

Fuente: elaboración propia (2017) a partir de Herández (2014, p. 79).

Seguidamente se procede a explicar cada una de las líneas que se desprenden del primer núcleo temático.

\section{Tipos de turismo}

Por añadidura se puede desprender que existen diversos tipos de turismo, tal y como lo menciona Quesada (2005), tomando en cuenta las motivaciones del turista y las necesidades de desarrollo de las diferentes regiones. 
Tabla 1. Tipos de turismo.

\begin{tabular}{|c|c|}
\hline Tipos & Descripción \\
\hline Cultural & $\begin{array}{l}\text { Es aquel en el cual se disfrutan las diversas } \\
\text { manifestaciones de arte y cultura, típicas de un país, zona } \\
\text { o localidad. }\end{array}$ \\
\hline Deportivo & $\begin{array}{l}\text { En el que se realizan prácticas o competencias deportivas } \\
\text { ya sea de manera individual o entre equipos. }\end{array}$ \\
\hline De placer & $\begin{array}{l}\text { Es aquella modalidad en que el motivo principal es el de } \\
\text { divertirse y disfrutar la plenitud de pasarla bien. }\end{array}$ \\
\hline De salud & $\begin{array}{l}\text { Es aquella que se caracteriza por condiciones de descanso, } \\
\text { recuperación, y mejoras de la salud. }\end{array}$ \\
\hline $\begin{array}{l}\text { De congresos y } \\
\text { convenciones }\end{array}$ & $\begin{array}{l}\text { Modalidad que consiste en realizar viajes con fines de } \\
\text { asistir a reuniones de diversa índole donde se combinan } \\
\text { las sesiones de trabajo con recorridos turísticos. }\end{array}$ \\
\hline De negocios & $\begin{array}{l}\text { Consiste en viajes que se realizan a otro lugar de } \\
\text { residencia no habitual, con el fin de gestionar o hacer } \\
\text { labores de una empresa. }\end{array}$ \\
\hline Naturalista & $\begin{array}{l}\text { Consiste en viajes que se realizan a otro lugar de } \\
\text { residencia no habitual, con el fin de gestionar o hacer } \\
\text { labores de una empresa. }\end{array}$ \\
\hline $\begin{array}{l}\text { De naturaleza } \\
\text { Suave (Soft } \\
\text { Nature) }\end{array}$ & $\begin{array}{l}\text { Consiste en los viajes que realizan las personas a un lugar } \\
\text { con atributos escénicos y naturales especiales, con el fin } \\
\text { de disfrutar esos recursos, pero sin realizar estudios o } \\
\text { investigaciones. }\end{array}$ \\
\hline $\begin{array}{l}\text { De naturaleza } \\
\text { Fuerte (Hard } \\
\text { Nature) }\end{array}$ & $\begin{array}{l}\text { Comprende los viajes a zonas naturales específicas } \\
\text { con el objetivo principal de investigar o reforzar sus } \\
\text { conocimientos respecto a un ecosistema, hábitat o } \\
\text { especie en particular. }\end{array}$ \\
\hline Ecoturismo & $\begin{array}{l}\text { Consiste en la protección del recurso natural aún siendo } \\
\text { visitado por turistas, contribuyendo así a su conservación, } \\
\text { y al sostenimiento de las comunidades aledañas que } \\
\text { desarrollan la actividad turística. }\end{array}$ \\
\hline
\end{tabular}

Fuente: Elaboración propia a partir de Quesada (2005, p. 101-107).

Como se puede visualizar, el turismo como actividad y hecho social se manifiesta de diversas formas, que están asociadas a las condiciones económicas, sociales, culturales e históricas de la zona geográfica. 
Un elemento importante que se debe considerar es que nuestro problema de investigación hace referencia a la provincia de Limón. Al momento de realizar alguna valoración sobre el desarrollo turístico de la zona es importante tener claridad sobre los diversos tipos de turismo, para poder determinar qué tipo de profesional es necesario para consolidar o renovar las necesidades del sector turismo.

\section{Gestión del turismo}

Es la segunda línea temática, la cual es definida por Arias (como se citó en Arauz 2010) la gestión del turismo debe ser "una gestión integral del espacio de modo tal que se mantenga un equilibrio entre los diferentes componentes (...) incluye procesos lógicos y vitales en toda organización tales como planear, organizar, dirigir y controlar" (p. 33).

Por consiguiente, la gestión del turismo se encarga de los procesos y actividades que se desprenden de este sector como actividad humana, social, económica, ambiental y cultural. La gestión del turismo puede generar de manera directa o indirecta, como señala Rivas y Magadán (2012), consecuencias que ven como resultado las comunidades receptoras, las cuales se clasifican en tres categorías: socioculturales, económicas y ambientales.

Como se puede evidenciar, surge la necesidad de formar profesionales que puedan responder a las necesidades progresivas que se presentan en el sector turismo en la provincia de Limón, debido a que el turismo es la principal actividad económica que provee el ingreso más fuerte en el país.

Es aquí donde se evidencia la importancia de diseñar un perfil profesional en turismo, siendo este el segundo núcleo del marco teórico. el cual se ilustra a continuación: 
Figura 3. Perfil profesional.

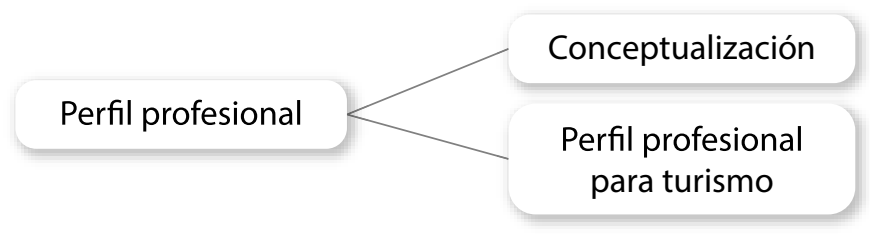

Fuente: Elaboración propia, 2017.

\section{Perfil profesional}

Diversas investigaciones que se han realizado tales como: Plan Nacional de Turismo Sostenible 2010-2016 (Instituto Costarricense de Turismo, 2018) y Plan Regional de Competitividad Territorial Región Huetar Atlántica Visión 2012-2022 (Junta de Administración Portuaria y de Desarrollo Económico de la Vertiente Atlántica, 2011), en los cuales se visualiza la situación actual de la región en temas económicos, sociales, culturales, entre otros, y contemplan los temas de interés prioritario a tomar en cuenta en la gestión de políticas públicas y acciones concretas para el desarrollo integral del territorio, señalan que las actividades asociadas al turismo deben ser planificadas y organizadas.

Se puede deducir que se debe invertir en la formación de profesionales nativos de la región capaces de planear, organizar, dirigir y controlar actividades asociadas al turismo.

Esto demuestra la pertinencia de elaborar un perfil profesional que satisfaga el desarrollo de la provincia y por ende del país.

Para Hernández (2004, p.107) el perfil profesional es la caracterización académica y personal del tipo de profesional que desea formar una institución de educación superior, para que responda a las necesidades, intereses y expectativas de tipo social, político, cultural, científico, tecnológico y laboral. 
Adicionalmente, Díaz señala que "el perfil profesional lo constituye un conjunto de conocimientos, habilidades y actitudes" (p.2). Ello con el fin de establecer los parámetros bajo los cuales el profesional de determinada área debe de desarrollarse en el ámbito laboral.

Valorando el aporte brindado por Hernández (2004) y Pérez e Izaguirre (2011) el perfil profesional es, el conjunto de conocimientos, habilidades y actitudes deseables que posea una persona que va recibir una formación educativa superior, para insertarse laboralmente de manera eficiente al desarrollo económico y social.

\section{Diseño}

Dentro de la estructura de esta investigación se comprende el diseño como el tercer núcleo de marco teórico, tal como se ejemplifica en la siguiente figura:

Figura 4. Diseño.

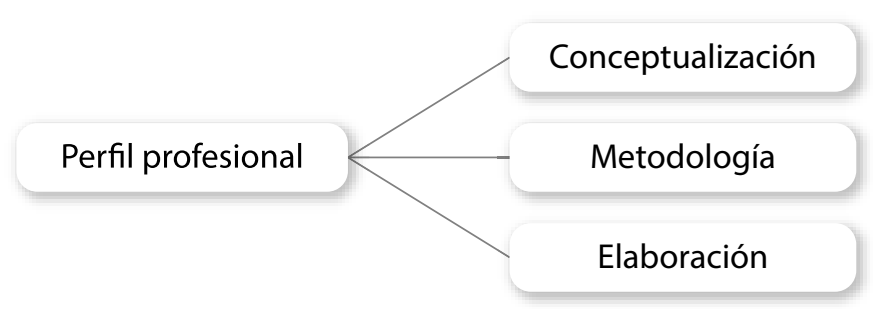

Fuente: Elaboración propia, 2017.

El diseño de un perfil profesional responde a un vacío que se encontró en diversas investigaciones analizadas, resumiéndose en la inexistencia de un perfil profesional actualizado para el distrito central de la provincia de Limón. 
Esta propuesta de perfil profesional se genera a partir de un conjunto de acciones políticas que se han generado en el seno de la provincia de Limón, con la creación de la Zona Económica Especial (ZEE) del Caribe la cual ha determinado cuatro sectores estratégicos: Turismo, Agroindustria, Logística y Alimentos Procesados. En virtud de lo anterior, turismo es considerado un sector estratégico, el cual debe ser atendido por medio de la preparación de diversos profesionales en distintos niveles de formación (Umaña, 2017).

Se busca crear una propuesta que articule de manera efectiva y racional sobre características, necesidades y perspectivas profesionales producto de un proceso de investigación que permita comprender las necesidades de un sector determinado como es el turismo en la provincia de Limón y propiamente en el distrito central.

Para efectos del diseño se va realizar una ruta de trabajo, que haga posible formular un perfil del profesional que responda a las demandas del sector turismo, que permita conocer los conocimientos, habilidades y destrezas deseables y que sean adquiridos dentro y fuera del ámbito de formación, sea de manera individual como colectiva.

Para elaborar un diseño de perfil profesional según señala el Instituto Peruano de Evaluación, Acreditación y Certificación de la Calidad de la Educación Básica (IPEBA, 2013) es importante tomar en cuenta: elementos, metodología y elaboración, estos serían los elementos de nuestra ruta de trabajo y por lo tanto, las líneas temáticas del diseño.

\section{Elementos del perfil profesional}

Son todos aquellos factores que son determinantes para el desarrollo de una profesión en particular, que se asocia con los conocimientos, habilidades y actitudes necesarias para el desempeño pertinente en el ámbito laboral. Entre los que se mencionan: 
Tabla 2. Elementos del perfil profesional.

\begin{tabular}{|c|c|}
\hline Elemento & Definición \\
\hline $\begin{array}{l}\text { Familia } \\
\text { profesional }\end{array}$ & $\begin{array}{l}\text { Conjunto de ocupaciones relacionadas entre sí, que } \\
\text { exigen conocimientos y habilidades. }\end{array}$ \\
\hline $\begin{array}{l}\text { Título } \\
\text { profesional }\end{array}$ & Nombre de la profesión reconocido y registrado. \\
\hline $\begin{array}{l}\text { Niveles de } \\
\text { competencia }\end{array}$ & $\begin{array}{l}\text { Grado de autonomía y responsabilidad de un trabajador } \\
\text { en el desempeño de su función, desde lo operacional a lo } \\
\text { gerencial. }\end{array}$ \\
\hline $\begin{array}{l}\text { Competencia } \\
\text { general }\end{array}$ & $\begin{array}{l}\text { En forma sintética expresa el quehacer del profesional } \\
\text { requerido en la ejecución de la profesión. Expresan } \\
\text { los conocimientos y habilidades característicos de la } \\
\text { profesión. }\end{array}$ \\
\hline
\end{tabular}

Capacitados
profesionales

Expresa requerimientos de calificación precisos que tiene

Unidades de
una persona en una profesión, según estándares de calidad.

competencia Son las actividades que se realizan, en un marco de Unidades de Competencia.

Realizaciones Identifica las tareas claves de cada realización para ver si el profesionales profesional alcanza un resultado descrito.

Criterios de
realización

El criterio de realización identifica las tareas claves propias de cada realización. Permite verificar si el profesional alcanza o no el resultado descrito.
Evolución previsible de profesión El avance de la tecnología y cambios en estructuras organizativas deben responder a condiciones laborales y venideras del sector.

Dominio profesional

Descripción del campo de aplicación de las realizaciones profesionales, describe los recursos y medios necesarios en la ejecución de las actividades inherentes a cada unidad de competencia profesional.

Fuente: . Elaboración según Instituto Peruano de Evaluación, Acreditación y Certificación de la Calidad de la Educación Básica (IPEBA, 2013). 
En términos simples, es el conjunto de herramientas de apoyo, que se pueden disponer para analizar y realizar un perfil profesional.

El Instituto Peruano de Evaluación, Acreditación y Certificación de la Calidad de la Educación Básica (IPEBA, 2013) señala que existen dos tipos de metodologías, es decir, el conjunto de pasos que se deben seguir para poder interpretar los datos suministrados a partir de la investigación realizada, para poder sistematizar los elementos del perfil profesional.

A continuación, se esquematizan las dos metodologías:

Figura 5. Metodologías para el diseño.

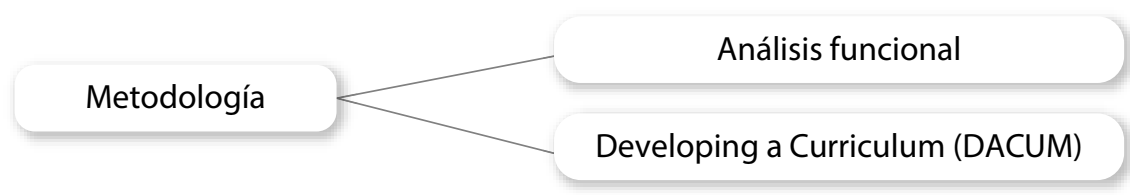

Fuente: Elaboración propia, 2017.

En términos generales el análisis funcional consiste en determinar las competencias laborales de un sector en específico, dentro de la investigación refiere a turismo y propiamente para la provincia de Limón. Dicho análisis se fundamenta en el árbol funcional ejemplificado de la siguiente manera: 
Figura 6. Árbol funcional.

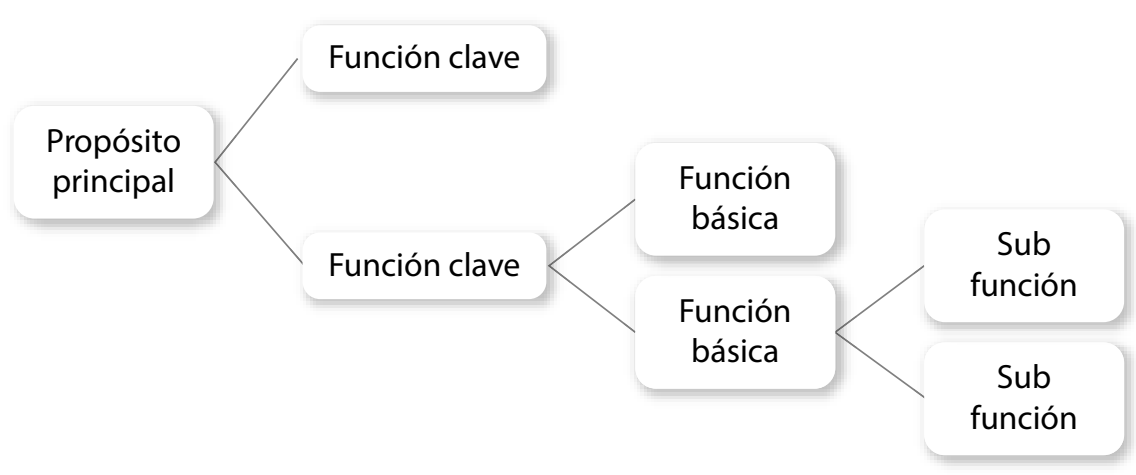

Fuente: Elaboración propia (2017) según Instituto Peruano de Evaluación, Acreditación y Certificación de la Calidad de la Educación Básica (IPEBA, 2013).

A continuación, se describe la finalidad de cada uno de los momentos ejemplificados en la figura anterior:

Tabla 3. Decripción del análisis funcional.

\begin{tabular}{|c|c|}
\hline Elemento & Definición \\
\hline $\begin{array}{l}\text { Propósito } \\
\text { principal }\end{array}$ & $\begin{array}{l}\text { Identificación de los principales objetivos del desarrollo } \\
\text { del sector. }\end{array}$ \\
\hline Funciones clave & $\begin{array}{l}\text { Funciones específicas que colaboran para alcanzar el } \\
\text { propósito principal. }\end{array}$ \\
\hline $\begin{array}{l}\text { Funciones } \\
\text { básicas }\end{array}$ & $\begin{array}{l}\text { ¿Para lograr el propósito principal, qué pasos requiero } \\
\text { dar?, las respuestas serán identificadas como funciones } \\
\text { claves. }\end{array}$ \\
\hline Sub función & $\begin{array}{l}\text { Establecer qué es lo que hace el trabajador para lograr el } \\
\text { proceso anterior. }\end{array}$ \\
\hline
\end{tabular}

Fuente: Elaboración propia (2017) según Instituto Peruano de Evaluación, Acreditación y Certificación de la Calidad de la Educación Básica (IPEBA, 2013 


\section{MÉTODOLOGÍA}

Tal y como se describe en el Manual para Elaborar Perfiles Profesionales, para efectos de la elaboración del diseño es importante tomar cuenta la siguiente estructura.

Figura 7. Metodologías para el diseño.

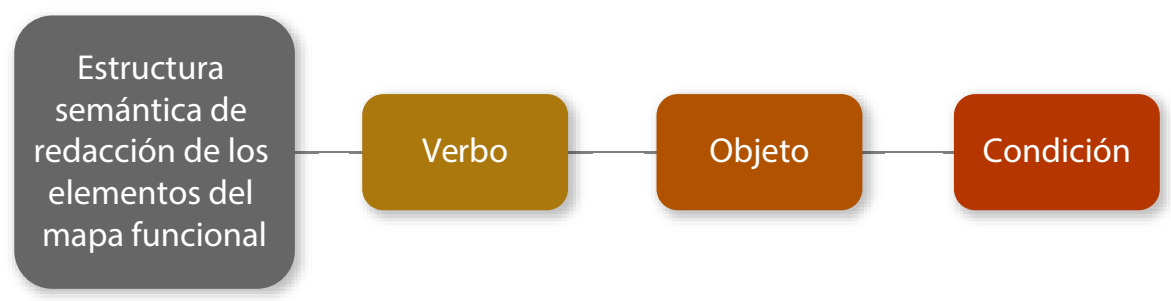

Fuente: Elaboración propia (2017) según Instituto Peruano de Evaluación, Acreditación y Certificación de la Calidad de la Educación Básica (IPEBA, 2013).

Por otra parte, la metodología DACUM (Developing a Curriculum) se puede comprender como el análisis de ocupaciones laborales y funcionales, definiendo las tareas y funciones. A partir de los expertos, facilitadores y registradores, todas estas personas nos van brindar el panorama general sobre las funciones y tareas propias del profesional, que nos permite diferenciar entre los conocimientos, habilidades y destrezas necesarias para el desarrollo del turismo.

En términos gráficos se puede ejemplificar a partir de la siguiente figura. 
Figura 8. Metodologías para el diseño.

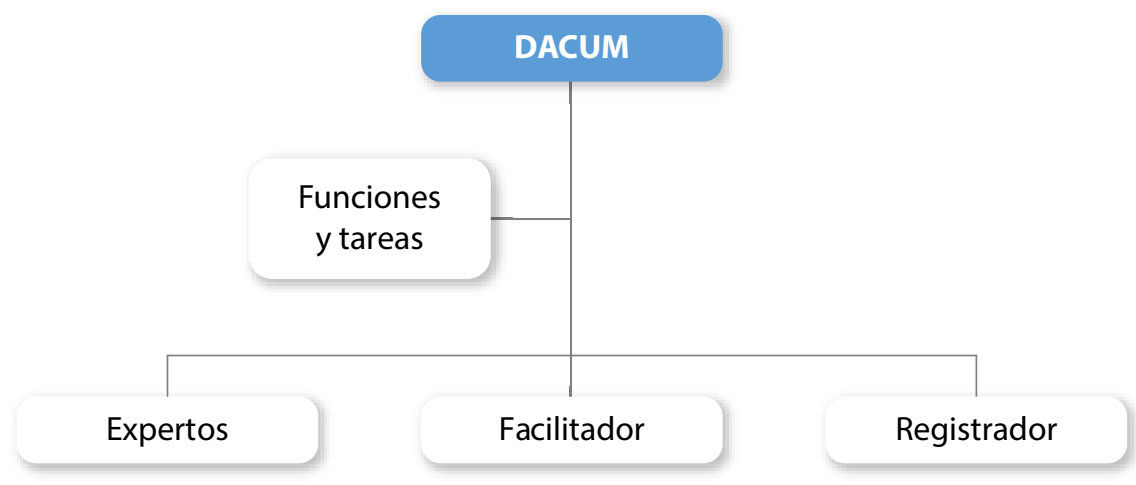

Fuente: Elaboración propia (2017) según Instituto Peruano de Evaluación, Acreditación y Certificación de la Calidad de la Educación Básica (IPEBA, 2013).

\section{Elaboración}

Como objetivo general de esta investigación se encuentra la formulación de un perfil profesional acorde para el sector turismo del distrito central del cantón principal de Limón.

Dicho perfil profesional “Es elaborado con la participación activa del sector productivo, siendo el referente para la información que se debe recoger sobre conocimientos, capacidades, habilidades, actitudes y valores que debe reunir un trabajador para el ejercicio de su profesión" (IPEBA, 2013, p. 28).

Se va a utilizar la herramienta denominada DACUM. Además, se escogió esta debido a que es una metodología que facilitará el diseño del perfil profesional, en este caso en el sector turismo. 
Tabla 4. DACUM para el proyecto de investigación.

\begin{tabular}{|c|c|c|c|c|}
\hline Objetivos & Tarea 1 & Tarea 2 & Tarea 3 & Tarea 4 \\
\hline $\begin{array}{l}\text { Formular } \\
\text { un perfil } \\
\text { profesional }\end{array}$ & $\begin{array}{l}\text { Búsqueda } \\
\text { de } \\
\text { información } \\
\text { teórica. }\end{array}$ & $\begin{array}{l}\text { Organizar la } \\
\text { información }\end{array}$ & $\begin{array}{c}\text { Proceso de } \\
\text { entrevista }\end{array}$ & $\begin{array}{c}\text { Sistematización } \\
\text { de la } \\
\text { información }\end{array}$ \\
\hline $\begin{array}{c}\text { Describir las } \\
\text { variables }\end{array}$ & & & $\begin{array}{l}\text { - Elaboración } \\
\text { - Aplicación }\end{array}$ & \\
\hline $\begin{array}{l}\text { Identificar las } \\
\text { características }\end{array}$ & ¿Para lograr & & $\begin{array}{c}\text { - Recopilación } \\
\text { de } \\
\text { información }\end{array}$ & \\
\hline
\end{tabular}

Fuente: Elaboración propia, 2017.

La tabla anterior permite disponer con detalle las tareas que se realizaron y se realizarán para cumplir con los objetivos planteados.

En la misma es posible observar que la primera tarea se basó en búsqueda de información teórica ello con el fin de tener bases para realizar una consulta congruente a la población, posterior a ello fue necesario organizar la información para dar seguimiento con el proceso de entrevista. Esta conlleva la elaboración, aplicación y recopilación de la información.

Finalmente, la sistematización de la información para obtener como resultado el perfil profesional adecuado al distrito central del cantón de Limón. 


\section{MÉTODO}

La importancia del turismo dentro de la investigación, la gestión y la formación académica en Turismo Sostenible radica en una actividad humana compleja, que abarca dimensiones sociales, económicos, políticas, culturales y ambientales complejas. Dado que el objetivo principal de esta investigación es generar aportes para la construcción de un perfil profesional en turismo, es necesario que se realice un estudio sobre las necesidades que enfrenta la actividad turística en la provincia de Limón y busque las posibles maneras de dar solución a los principales problemas asociados a esa actividad del ocio y la recreación. Para ello se tomó en cuenta diferentes puntos de vista de profesionales que trabajan tanto dentro y fuera de la zona de estudio, ya sea de forma directa o indirecta y que estuviesen asociados con la actividad turística.

\section{Paradigma de investigación}

Esta investigación se realiza desde la carrera de Gestión del Turismo Sostenible que se imparte en la Escuela de Ciencias Sociales del Instituto Tecnológico de Costa Rica, ya que "el turismo se ocupa de aspectos humanos considerados de manera individual y colectiva, tal y como lo hace las ciencias sociales, de las cuales el turismo adopta contenidos y herramientas" (Corominas \& Pascual; citado por Martínez, 2013, p.3).

De acuerdo con lo anterior, el paradigma de esta investigación es considerado como naturalista ya que permite interpretar con la teoría los procesos y relaciones socioculturales, económicas, políticas y ecológicas $y$, de esta manera, ampliar en conocimiento y las principales tareas a realizar. Es decir, dotar de significado a las acciones humanas dentro de una práctica social, propiamente a las acciones y las percepciones que se generan desde la actividad o las actividades que se generan del turismo.

En otras palabras, el desafío es utilizar nociones propias de dicho paradigma, como comprensión y significación para descubrir la conexión e interconexión entre los elementos de la investigación, por medio de la aplicación de entrevistas y cuestionarios a diversas personas que se vinculan con entidades e instituciones involucradas. 
Por lo tanto, dentro del trabajo que se plantea existe una estrecha relación entre los investigadores, los sujetos investigados y participantes del proceso, tal como señala García (2010), "las personas que investigan de modo natural, lo hacen para evidenciar la realidad tal y como ellos y ellas la viven".

Es importante aclarar que la investigación está centrada en describir, interpretar, comprender, analizar y formular las particularidades que se encuentran implícitas en la percepción del fenómeno del turismo, por lo que se podrá ir construyendo poco a poco el diseño del perfil profesional.

Según expresa Barrantes (2012) respecto del método naturalista, en lugar de tener control sobre la comprensión, significado y acción sucede todo lo contrario, la concepción de mundo que se maneja es "dinámica, múltiple y holística".

Cabe destacar que el significado y comprensión de las percepciones que están sujetas a la conexión que se dé entre los elementos estudiados y los sujetos de la investigación sirven para construir una concepción del perfil profesional para atender las necesidades del sector turismo del distrito central de la provincia de Limón. En este sentido, se utilizan diversos procesos tales como observación, aplicación de entrevistas y la interpretación, correlación de los datos.

\section{Enfoque de la investigación}

Esta investigación se basó en un enfoque cualitativo, de acuerdo a la elección del paradigma naturalista, teniendo claro que el objetivo principal no es cuantificar datos; sino recolectar y analizar la información. Dicho enfoque consiste "en métodos de recolección de datos no estandarizados ni predeterminados completamente" (Hernández, et al 2014 , p.8). Debido a la naturaleza de la investigación, la recolección de datos tuvo como finalidad obtener las perspectivas y puntos de vista de las y los participantes. 
En estudios naturalistas se muestran, narran, reseñan o identifican hechos, situaciones, rasgos, características de un objeto de estudio, o se diseñan productos, modelos, prototipos, guías, etcétera, pero no se dan explicaciones o razones de las situaciones, los hechos, los fenómenos, etcétera (Bernal, 2006, p.113).

Es decir, esta investigación recopila información sobre diversos aspectos relacionados con el perfil de profesional en turismo, así como el desarrollo turístico de Limón. Además, se construye una propuesta de perfil profesional dotada de validez a partir de la proximidad con la realidad que se estudia, dando como producto final un documento que integra los requerimientos del sector en la actualidad de la provincia de Limón, en ese país centroamericano.

\section{Tipo de Investigación}

Acorde con el problema y los objetivos planteados, el tipo de investigación es etnográfica, porque se busca interpretar las percepciones sobre: turismo a nivel general, preparación de profesionales en turismo y sobre el desarrollo turístico.

De manera puntual García (2010, p. 16) señala que dicho tipo de investigación, [...] pretende construir descripciones de fenómenos globales en diversos contextos y determinar, a partir de ellas, complejas conexiones que afectan el comportamiento de las creencias en relación con los fenómenos.

Habría que decir también, que es una forma particular de abordar el objeto de estudio o problema planteado que conlleva un proceso y conjunto de niveles, como se muestra en la Figura 9: 
Figura 9. Niveles de investigación etnográfica.

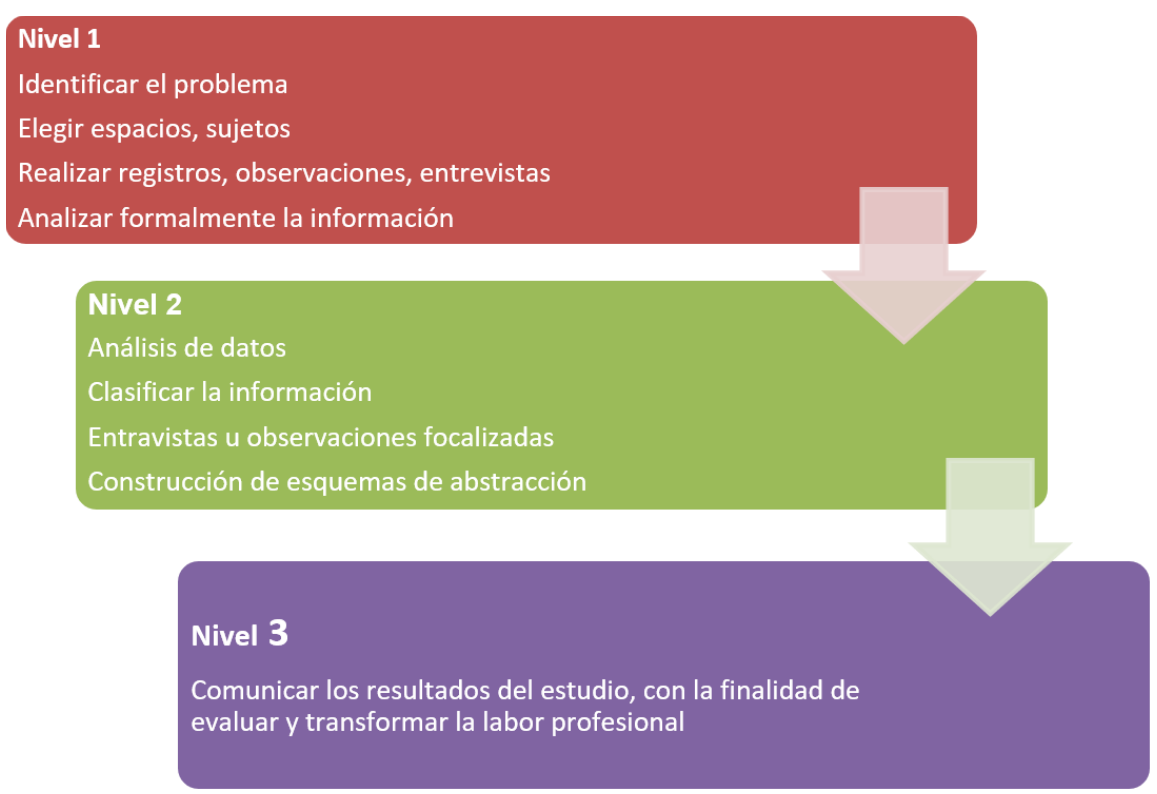

Fuente: Elaboración propia a partir de información obtenida en García (2010).

Con el fin de comprender la figura anterior, a continuación, se explican cada uno de los niveles de la investigación etnográfica:

Nivel 1: Aborda acciones tales como identificación, elección de sujetos y espacios, recopilación y análisis de la información obtenida.

Nivel 2: Se enfoca en el análisis, clasificación y sistematización de datos obtenidos por medio de técnicas de investigación.

Nivel 3: Divulgación de la información con la finalidad de evaluar y transformar a nivel la labor profesional.

La siguiente tabla muestra la relación del tipo de técnicas utilizadas en la investigación: 
Tabla 5. Relación tipo de investigación, enfoque y técnicas.

\begin{tabular}{|c|c|c|}
\hline Tipo de investigación & Enfoque & Técnicas \\
\hline Etnografía & Cualitativo & $\begin{array}{l}\text { - Entrevista estructurada } \\
\text { - Cuestionario } \\
\text { - Cuestionario auto } \\
\text { administrativo }\end{array}$ \\
\hline
\end{tabular}

Fuente: Elaboración propia a partir de trabajo de campo realizado en 2017.

Por otra parte, se utilizó la técnica del cuestionario la cual "consiste en un conjunto de preguntas respecto de una o más variables a medir y este debe de ser congruente con el planteamiento del problema e hipótesis" como lo mencionan Chasteauneuf (2009) y Brace (2013) (citados por Hernández et al, 2014, p.217). Se utilizan para calificar y conocer las necesidades, así como para evaluar la percepción de la población en cuestión; a modo tal que estos aporten opiniones con el fin de contribuir en el proceso investigativo.

Además, es importante mencionar que el cuestionario utilizado se ha modificado y reestructurado dependiendo de los sujetos, el lugar y contexto en el que se recolectaron los datos, y sus variables han sido mantenidas según el problema de investigación.

Finalmente, la técnica utilizada fue el cuestionario auto administrado que, tal y como lo menciona Hernández (2014), esta técnica se basa en proporcionar directamente a los participantes el instrumento, quienes lo contestan de manera directa y sin intermediarios. La forma de autoadministración de dicha técnica puede tener distintos contextos y en la presente investigación se envió por correo electrónico. 
Tabla 6. Técnicas para la recopilación de información.

\begin{tabular}{|c|c|}
\hline Población & Técnica \\
\hline Sector Educativo & Entrevistas \\
\hline Sector Empresarial & Entrevistas y cuestionarios \\
\hline Sector Gobierno Local & Entrevistas \\
\hline Sector no Formal & Entrevistas y cuestionarios \\
\hline Graduados en GTS & Cuestionarios autoadministrados \\
\hline Profesionales en Turismo & Cuestionarios autoadministrados \\
\hline
\end{tabular}

Fuente: Elaboración propia a partir de trabajo de campo realizado en 2017.

Lo dicho hasta aquí supone que la aplicación de diversas técnicas a través de las cuales se va obtener información permitir construir descripciones y relaciones para analizar el contexto desde una perspectiva que nos permita establecer de manera progresiva el perfil profesional.

Se adopta una perspectiva etnográfica, partiendo de un estudio en un momento dado, tratando de descubrir los motivos y las percepciones sobre el turismo para que, de manera progresiva, se pueda ir dotando de significado dichas percepciones, desde una postura crítica y analítica sobre el turismo del distrito central de Limón.

\section{Instrumentos para la recopilación de la información}

Esta sección está constituida por los siguientes elementos: descripción y validación de los instrumentos.

En este contexto, se define instrumento de medición como "aquel que registra adecuadamente datos observables que representan verdaderamente los conceptos o variables que el investigador tiene en mente" (Hernández et al, 2014, p.276). 
Para efectos de la investigación se realizó una entrevista estructurada y dos cuestionarios, los cuales abordaron temáticas específicas, como se indica seguidamente:

Tabla 7. Estructura de Instrumentos según variables de estudio.

Instrumento

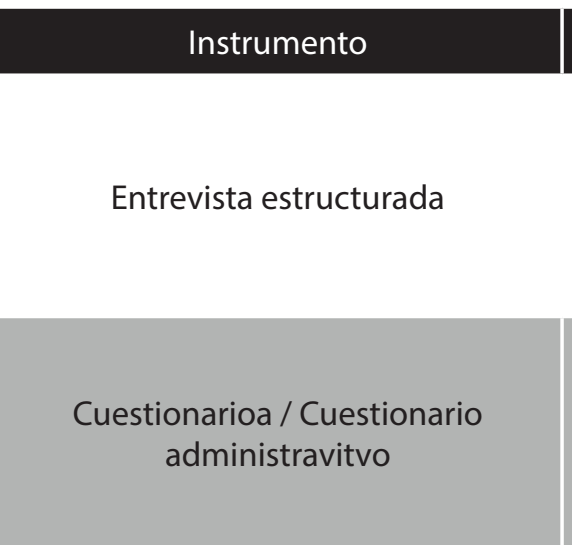

Vriables de estudio

- Situación actual del desarrollo turístico de Limón - Situación actual del distrito central - Características generales deseables de un profesional de turismo

- Percepción del turismo en general. - Valoración sobre la preparación de profesionales en turismo - Percepción del desarrollo turístico

Fuente: Elaboración propia a partir de trabajo de campo realizado en 2017.

La recolección y registro de la información en este estudio se llevó a cabo mediante entrevistas y cuestionarios los cuales están compuestos, según Hernández et al (2014), tanto de preguntas abiertas cómo de preguntas cerradas; además del cuestionario auto administrado que se proporcionó a los participantes por medio del correo electrónico.

Para una mejor comprensión de los apartados que forman parte del instrumento se realiza una breve descripción de los mismos:

- La entrevista estructurada se dividió en apartados que se centraron específicamente en conocer la situación actual de la provincia de Limón, así como el distrito central, en términos de desarrollo turístico, mostrando vital interés en conocer las características de un profesional en turismo. 
- Los cuestionarios hacen mención del sector turismo de manera general para comprender la percepción, valoración, desarrollo turístico y la preparación del perfil profesional requerido en esa provincia del Caribe costarricense.

Tabla 8. Instrumentos de investigación según tipo de Ítem y sujetos entrevistados.

\begin{tabular}{|c|c|c|c|}
\hline Instrumento & Tipo de ítem & Cantidad & Sujetos \\
\hline Entrevista & Abierto & 19 & Sector Educativo \\
\hline Entrevista y & Abierto & 18 & \multirow{2}{*}{ Sector Empresarial } \\
\cline { 2 - 4 } cuestionario & Cerrado & 2 & \\
\hline \multirow{2}{*}{ Entrevista } & Abierto & 18 & Sector Gobierno Local \\
\hline \multirow{2}{*}{ Entrevista y } & Cerrado & 2 & \\
cuestionario & Abierto & 18 & Sector no Formal \\
\hline
\end{tabular}

Fuente: Elaboración propia a partir de trabajo de campo realizado en 2017.

La elaboración y adecuación de cada uno de los instrumentos tiene una intención metodológica y analítica tal como señala Armas et al (2009, p. 16): A través de la comprensión se pretende penetrar en las relaciones internas y profundas de los fenómenos que se estudian e; indagar en la intencionalidad de las acciones. O sea que, para comprender el significado de la conducta de una persona, el investigador intenta interpretar los hechos sociales desde la perspectiva del sujeto. Se considera importante que los esquemas de interpretación procedan de los sujetos y no de los investigadores. Para ello fue necesario reconstruir las categorías que utilizaron los participantes para conceptualizar sus experiencias.

De manera tal que, para efectos de la investigación, los instrumentos utilizados han sido dirigidos a sujetos con conocimientos teóricos y prácticos, que fueron capaces de brindar información que ayudó a resolver el problema de investigación. 


\section{DISCUSIÓN Y RESULTADOS}

Los resultados tienen relación directa con el problema planteado, que consistió en responder la siguiente pregunta: ¿Cuál es el perfil profesional que requiere el sector turismo en el distrito central del cantón de Limón?

Los resultados se interpretaron en tres etapas:

En primer lugar, se simplificó la información por medio de la sistematización y organización de los datos más relevantes en relación con los objetivos propuestos.

Se extrajo la información relevante para responder al problema en cuestión, además se identificaron insumos que facilitaron el análisis de los elementos necesarios para formular un perfil profesional acorde al campo académico del turismo desde el contexto del distrito central del cantón de Limón.

Los objetivos que guiaron esta investigación cualitativa fueron los siguientes:

- Describir las variables del perfil profesional que se generan en el sector turismo del distrito central de la provincia de Limón.

- Identificar el tipo de conocimiento, habilidades y valores que caracterizan el perfil profesional en el sector turismo del distrito central de la provincia de Limón.

- Establecer un perfil profesional acorde a las necesidades que se generan en el sector turismo del distrito central de la provincia de Limón.

En segundo lugar, el propósito de este trabajo fue encontrar las líneas temáticas o categorías de análisis que permitieran justificar y organizar una propuesta acorde con el problema planteado.

Las categorías de análisis establecidas a partir de los objetivos y de los datos encontrados en la investigación son los siguientes: 
Figura 10. Sistematización de resultados.

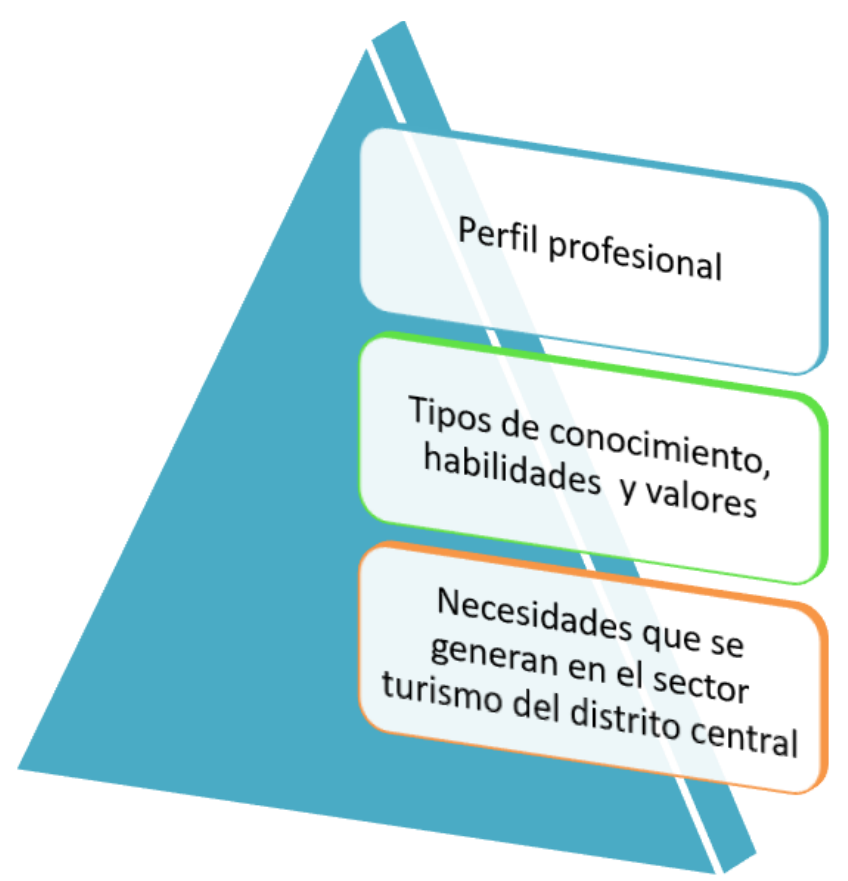

Fuente: Elaboración propia a partir de información obtenida en García (2010).

La siguiente sección corresponde a información procesada bajo el método de tabulación de las entrevistas realizadas a distintas personas que representan a los sectores sociales con lo que se trabajó en la aplicación de los instrumentos elaborados, los cuales fueron aplicados de manera personal. Cabe destacar que los sujetos entrevistados en la primera labor de campo compartieron características en común, entre ellas: que pertenecen a la provincia de Limón y, además, se ubican dentro de sectores como: Educación, empresarial, gobierno local y turismo.

La información recolectada permitió que la muestra con la que se contó fuera sea confiable para efectos de este proceso de análisis de datos de la investigación, a partir de conocer sobre la percepción actual del desarrollo turístico de Limón y, en especial, del distrito central, la cual permite determinar características generales deseables dentro de un perfil del profesional de turismo. 
A través de la investigación realizada y de los datos recopilados por medio de los distintos instrumentos aplicados a los diferentes sectores anteriormente establecidos, la información se analizó según los objetivos de la investigación:

\section{Primer Objetivo}

- Describir las variables del perfil profesional que se generan en el sector turismo del distrito central de la provincia de Limón.

Se logra comprender que la actividad turística ha aumentado en los últimos años a nivel mundial, en Costa Rica no es la excepción de hecho es la actividad económica de servicios más importante. De igual manera, la actividad turística en la provincia de Limón ha aumentado considerablemente en los últimos tiempos. Paralelo a este aumento se encuentra un factor que no da estabilidad, por lo que no se ha visto beneficiado todo el Caribe, sino mayoritariamente en el Caribe norte y sur, pero no sucede este mismo aumento en el área del cantón central. Por lo tanto, los beneficios de dicha actividad no se han visto repartidos de forma equitativa en la provincia.

Además, se logra definir una serie de cualidades que debería tener un profesional del sector turismo, visto a través de la visión de continuar con el aumento de la productividad del sector, entre las cuales destacan: la capacidad de tomar decisiones con respecto al ajuste de la situación actual de este distrito, de relacionarse en equipo y tener una cultura hospitalaria.

Otras variables son consideradas como dinámicas, lo que quiere decir que el turismo en esta provincia depende de cualidades muy especiales, sobre todo en cualidades académicas o profesionales en el área de manejo de recurso natural, impacto ambiental y las realidades de adaptación al cambio. 


\section{Segundo Objetivo}

- Identificar el tipo de conocimiento, actitud y habilidad que caracteriza el perfil profesional del sector turismo del distrito central de la provincia de Limón.

Se concluye que, al identificar las diversas características de un perfil profesional para el distrito central de Limón, que requieren de conocimientos en diversas áreas, entre ellas se encuentran: mercadeo, idiomas y administración de empresas turísticas.

Por otra parte, son necesarios, según los sujetos consultados, los conocimientos en planificación estratégica para el desarrollo de planta turística, infraestructura turística y los diferentes atractivos turísticos de la zona, con el fin de lograr un desarrollo adecuado en el sector turismo del distrito central de Limón. De este modo, se requiere que el perfil del profesional en el sector sea capaz de gestionar diversos proyectos relacionados con la dinámica del turismo.

De manera semejante, los resultados señalaron que la zona de Limón requiere personal capacitado en cuanto a la prestación de servicios, ya que el conocimiento en esta área es esencial para la satisfacción del cliente y para generar un posicionamiento en el mercado.

Otra característica necesaria en el perfil de un profesional en turismo es la habilidad, entiéndase esta, como un conocimiento que se adquiere con la práctica de una labor. De acuerdo a los sujetos entrevistados, las habilidades con las que debe de contar un profesional en turismo serían: tener una visión emprendedora, tener habilidad de comunicación oral y escrita, habilidad de relacionarse con las demás personas y trabajar de forma conjunta con un equipo de trabajo.

A su vez, la actitud es un componente importante en la formulación de un perfil profesional, la cual se entiende como la disposición afectomotivacional que provoca que un individuo labore con eficiencia, eficacia y efectividad. 
Considerando lo anterior, los entrevistados acotan que las principales actitudes que permiten el desarrollo adecuado de la actividad turística en el distrito central de Limón son: liderazgo, amabilidad, deseo de superación, imaginación, respeto, compañerismo y responsabilidad. Es conveniente subrayar que estas actitudes proporcionan una mejor calidad de los servicios brindados; estas dependen de la disposición con que cuente el profesional para desarrollarse en su lugar de trabajo.

\section{Tercer Objetivo}

- Establecer un perfil profesional acorde a las necesidades que se generan en el sector turismo del distrito central de la provincia de Limón.

Con base en este objetivo se estableció que los conocimientos que debería desarrollar un perfil profesional en el sector turismo del distrito central deben incorporar al patrimonio y la cultura propia del Caribe de Costa Rica, tener un conocimiento teórico básico sobre qué es el turismo; además de estar preparado para gestionar labores en el área administrativa, tecnológica y sostenible principalmente. 
Tabla 9. Propuesta de perfil profesional del turismo para el distrito central de Limón.

\begin{tabular}{|c|c|c|c|c|c|c|c|}
\hline \multirow{2}{*}{\multicolumn{2}{|c|}{ Conocimientos }} & \multicolumn{6}{|c|}{ Características } \\
\hline & & 1 & 2 & 3 & 4 & 5 & 6 \\
\hline A & $\begin{array}{l}\text { Patrimonio y } \\
\text { cultura }\end{array}$ & $\begin{array}{c}\text { Conocer de } \\
\text { manera crítica } \\
\text { la historia de la } \\
\text { provincia }\end{array}$ & $\begin{array}{l}\text { Saber cuáles } \\
\text { son las } \\
\text { tradicoines } \\
\text { y festejos } \\
\text { populares } \\
\text { del cantón y } \\
\text { provincia. }\end{array}$ & $\begin{array}{l}\text { Conocer el } \\
\text { patrimonio } \\
\text { tangible e } \\
\text { intangible de la } \\
\text { provincia. }\end{array}$ & $\begin{array}{l}\text { Gestionar y } \\
\text { administrar } \\
\text { de forma } \\
\text { adecuada } \\
\text { el patrimonio. }\end{array}$ & $\begin{array}{c}\text { Crear } \\
\text { atractivos } \\
\text { para que el } \\
\text { turista visite la } \\
\text { provincia de } \\
\text { Limón. }\end{array}$ & $\begin{array}{l}\text { Rescatar } \\
\text { prácticas } \\
\text { tradicionales }\end{array}$ \\
\hline B & Administración & $\begin{array}{l}\text { Conocer de } \\
\text { mercadeo }\end{array}$ & $\begin{array}{c}\text { Saber de } \\
\text { contabilidad y } \\
\text { finanzas }\end{array}$ & $\begin{array}{c}\text { Logística y } \\
\text { administración } \\
\text { portuaria. }\end{array}$ & $\begin{array}{c}\text { Conocer } \\
\text { perfectamente } \\
\text { el uso de } \\
\text { Tecnologías de } \\
\text { Información y } \\
\text { Comunicación } \\
\text { (TIC's). }\end{array}$ & $\begin{array}{c}\text { Tener } \\
\text { conocimiento } \\
\text { en Recursos } \\
\text { Humanos. }\end{array}$ & Ser innovador \\
\hline $\mathrm{C}$ & Gestión & $\begin{array}{c}\text { Planificación y } \\
\text { evaluación de } \\
\text { proyectos }\end{array}$ & $\begin{array}{c}\text { Generar planes } \\
\text { de desarrollo }\end{array}$ & $\begin{array}{l}\text { Capacidad para } \\
\text { diseñar planes } \\
\text { de trabajo. }\end{array}$ & $\begin{array}{l}\text { Capacidad de } \\
\text { asesoramiento }\end{array}$ & $\begin{array}{l}\text { Ser capaz de } \\
\text { solucionar } \\
\text { problemas. }\end{array}$ & $\begin{array}{c}\text { Atender } \\
\text { situaciones } \\
\text { y diseñar } \\
\text { estrategias } \\
\text { de desarrollo } \\
\text { sostenible. }\end{array}$ \\
\hline D & Sostenibilidad & $\begin{array}{c}\text { Capacidad } \\
\text { para evaluar la } \\
\text { sostenibilidad } \\
\text { de los } \\
\text { proyectos }\end{array}$ & $\begin{array}{l}\text { Manejo de } \\
\text { recursos } \\
\text { naturales, } \\
\text { impacto en } \\
\text { realidades } \\
\text { humanas y } \\
\text { ambientales. }\end{array}$ & $\begin{array}{c}\text { Concientización } \\
\text { ambiental }\end{array}$ & $\begin{array}{l}\text { Capacidad } \\
\text { para trabajar } \\
\text { con grupos. }\end{array}$ & $\begin{array}{c}\text { Diseñar } \\
\text { estrategias } \\
\text { de desarrollo } \\
\text { sostenible. }\end{array}$ & $\begin{array}{c}\text { Coordinar } \\
\text { acciones } \\
\text { sustentables } \\
\text { para generar } \\
\text { mejores } \\
\text { oportunidades } \\
\text { en lugares } \\
\text { con menor } \\
\text { visitación } \\
\text { turística de } \\
\text { Limón }\end{array}$ \\
\hline$E$ & Tecnología & $\begin{array}{l}\text { Conocimientos } \\
\text { básicos en } \\
\text { computación }\end{array}$ & $\begin{array}{c}\text { Operar } \\
\text { software } \\
\text { que ayuden } \\
\text { en diferentes } \\
\text { labores } \\
\text { turísticas. }\end{array}$ & $\begin{array}{c}\text { Manejo de } \\
\text { software para } \\
\text { el desarrollo } \\
\text { de actividades } \\
\text { turísticas. }\end{array}$ & $\begin{array}{c}\text { Uso de la } \\
\text { tecnología } \\
\text { para la } \\
\text { promoción del } \\
\text { turismo en la } \\
\text { zona. }\end{array}$ & $\begin{array}{c}\text { Mantener un } \\
\text { uso adecuado } \\
\text { con la } \\
\text { aplicación de } \\
\text { la tecnología } \\
\text { en áreas de } \\
\text { desarrollo del } \\
\text { turismo. }\end{array}$ & \\
\hline
\end{tabular}




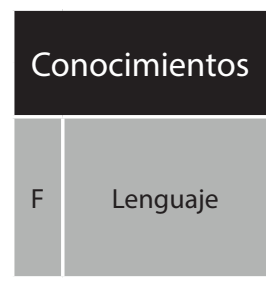

\begin{tabular}{|c|c|}
\hline 1 & 2 \\
\hline $\begin{array}{c}\text { Comunicación } \\
\text { oral y escrita }\end{array}$ & $\begin{array}{c}\text { Manejo de } \\
\text { idioma iglés } u \\
\text { otros }\end{array}$ \\
\hline
\end{tabular}

Tipos de

turismo que

G Turismo

Historia del
turismo existen y cuáles son aquellos que se dan en la provincia.

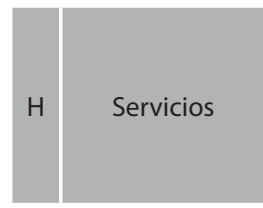

\section{Cultura} hospitalaria y promover la venta de producto local.

\begin{tabular}{|c|c|c|}
\hline \multicolumn{3}{|c|}{ Características } \\
\hline 3 & 4 & 5 \\
\hline $\begin{array}{c}\text { Capacidad de } \\
\text { expresarse } \\
\text { correctamente. }\end{array}$ & $\begin{array}{c}\text { Correcto } \\
\text { lenguaje } \\
\text { corporal y } \\
\text { gestualidad. }\end{array}$ & $\begin{array}{c}\text { Lenguaje } \\
\text { LESCO }\end{array}$ \\
\hline
\end{tabular}

Elementos del turismo

Tener
capacidades
analíticas

Debe de aprender Psicología humana.
Principales actividades turísticas de Limón.

Liderazgo en
servicios.

6

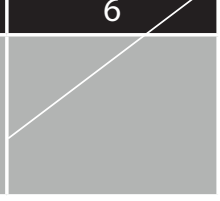

Turismo

mundial e inclusivo

Contar con gerente de servicios

Fuente: Elaboración propia a partir de trabajo de campo realizado en 2017. 


\section{CONCLUSIONES}

El presente trabajo demuestra el aporte a diversas áreas del profesional de turismo que se requieren en el distrito central de la provincia de Limón, en donde existe una gran exigencia por satisfacer las necesidades de servicios y mejorar la calidad de vida de muchos habitantes del Caribe costarricense. Por medio de esta investigación se determinó que los actores sociales entrevistados presentan un conocimiento amplio en la realidad turística del cantón; sobre todo, con en el conocimiento de los proyectos necesarios para el desarrollo de la provincia a largo plazo. La propuesta tiene fundamentación teórica que evidencia la necesidad de teorías en relación al tema propuesto y adecuadas al territorio en estudio.

El trabajo que se ha realizado hasta el momento brinda aportes dentro de la investigación académica en turismo. Los aportes de esta investigación se orientan a la producción de conocimiento acerca del turismo en el distrito central de la provincia de Limón, ya que la apertura del Campus Tecnológico Local en el distrito se encuentra con posibilidades de tomar en cuenta la profesionalización del sector en su sede y crear bajo las condiciones adecuadas una oferta educativa crítica, propositiva y competitiva tanto para sus estudiantes nacionales como la oferta internacional, tomando en cuenta los avances existentes.

En segundo lugar, un sector que se podría llegar a beneficiar es el sector de empresarios de turismo que brindó información sobre el perfil del profesional que conocían al momento de la realización de esta investigación y acerca de la actividad económica que se asocia específicamente con las actividades turísticas.

En tercer lugar, se da un aporte al sector del gobierno local que puede tomar ventaja para apoyar el crecimiento del sector turismo dentro del distrito central de la provincia de Limón y así mejorar la imagen y las condiciones de sociales, culturales y ambientales del distrito.

El ITCR, con su carrera de Gestión de Turismo Sostenible, impartida en la sede central dispondrá de un nuevo material derivado de esta investigación que hace un aporte para futuros investigadores que deseen continuar con nuevos proyectos asociados al sector turismo en el distrito central de la provincia de Limón. 


\section{BIBLIOGRAFÍA}

Arauz, I. (2010). Análisis del Sistema Turístico del Cantón de Buenos Aires: Insumo para un Diseño de Plan de Desarrollo en Turismo Rural. Buenos Aires.

Armas, R. et al (2009). Dos formas de orientar la investigación en la educación de postgrado: lo cuantitativo y lo cualitativo. Revista Pedagogía Universitaria, 15(5): 13-28, 2010. La Habana, CU: Editorial Universitaria. Retrieved from http://www.ebrary.com

Barrantes, R. (2012). Investigación: un camino al conocimiento, un enfoque cuantitativo y cualitativo. San José, Costa Rica: EUNED.

Bernal Torres, C. A. (2006). Metodología de la investigación para administración, economía, humanidades y ciencias sociales. Publicado por Pearson Educación. Colombia.

Chaverri, L. (2018). Centro histórico de puerto Limón, transformaciones sociales que han contribuido a su patrimonización. Revista Trama. Volumen (8),107-149.

Díaz-Barriga (2011). Metodología de diseño curricular para educación superior. México, D.F.:Trillas.

García Fallas, J., et al (2010). Investigación-acción colaborativa: Un encuentro con el quehacer cotidiano del centro educativo para su transformación. SJ, CR: INIE.

Guerrero González, P. E., Y Ramos Mendoza, J. R. (2014). Introducción al turismo. México, D.F: Grupo Editorial Patria.

Guzmán, T., Fernández, M., Villalobos, J., Monreal, I., Rivero, M. y Blanco, A. (2015). Nueva Oferta educativa como respuesta al desarrollo del país: Ingeniería Agroindustrial. Tecnología en Marcha. 29(3). 47-59. DOI: http://dx.doi. org/tm.v29i3.2887

Hawes, B., \& Corvalán, O. (2005). Construcción de un Perfil Profesional. Recuperado de http://www.iide.cl/medios/ iide/publicaciones/revistas/Construccion_de_un_Perfil_Profesional.pdf

Hernández, A. (2004). Perfil profesional. Capítulo V. Revista Pedagogía 9 (2): 69-98.
Hernández, R. Fernández, C y Baptista, P. (2014). Metodología de la Investigación. Ciudad de México, México, Edificio Punta Santa Fe.

Instituto Costarricense de Turismo. (2018). Plan Nacional de Turismo Sostenible de Costa Rica. Recuperado de http://www.ict.go.cr/es/documentos-institucionales/plan-nacional-y-planes-generales/ plan-nacional-de-desarrollo/resumen-plan-nacional-de-turismo-sostenible-2010-2016/35-resumen-plan-nacional-de-turismo-sostenible-2010-2016/file.html

Instituto Peruano de Evaluación, Acreditación y Certificación de la Calidad de la Educación Básica. (2013). Manual para elaborar perfiles profesionales (Primera ed.). Lima, Perú.: Talión Print E.I.R.L.

Jensen, A. (2004). Diagnóstico de las necesidades de capacitación y desarrollo de los afiliados a la Cámara Nacional de Turismo en Costa Rica: recomendaciones generales al comité de capacitación. Posgrado Universidad de Costa Rica

Jiménez, L. y Jiménez, W. (2013) Turismo: Tendencias Globales y Planificación Estratégica. Bogotá: Ecoe Ediciones.

Junta de Administración Portuaria y de Desarrollo Económico de la Vertiente Atlántica. (2011). Plan Regional de Competitividad Territorial Región Huetar Atlántica Visión 2012-2022. Recuperado de http://www. japdeva.go.cr/administracion_de_desarrollo/promocion_del_desarrollo_regional/plan_regional_de_desarrollo/3\%20El\%20Plan\%20Regional.pdf

Lao, J. (2012). Investigación de mercados. Determinación del perfil profesional académico carrera sobre turismo. (P.1-26)

Martínez, J. (2013). El turismo como Ciencia. Universidad de Málaga, p.1-11. ISBN-13:978-84-15774-50-1 
Orozco, J., y Núñez, P. (2013). Las Teorías del desarrollo: En el análisis del turismo sustentable. Intersedes.Vol.14 (27).

Pérez, S., e Izaguirre, R. (2009). Modelo Andragógico. Fundamentos. Universidad Valle de México. Editorial: Ma. Guadalupe Ambriz. México DF.

Programa Estado de la Nación (2015). Informe Estado de la Nación en Desarrollo Humano Sostenible: San José, Costa Rica. Recuperado de http://www.estadonacion. or.cr/21/assets/pen-21-2015-baja.pdf

Programa Estado de la Nación (2019). Informe Estado de la Nación en Desarrollo Humano Sostenible: San José, Costa Rica.

Quesada Castro, R. (2005) Elementos del Turismo. San José: Editorial Universidad Estatal a Distancia

Rivas, J. y Magadán, M. (2012). Planificación Turística y Desarrollo Sostenible. Recuperado de http://ezproxy. itcr.ac.cr:2138/visor/35510

Tamayo, M. (2012). El proceso de la investigación científica. (5 Ed.). México, D.F., México: Limusa, S. A

Umaña, J. (2017). Limonenses se comprometen a potencial el desarrollo de la provincia. Lanzamiento de la Zona Económica Especial del Caribe. Hoy en el TEC. Recuperado de https://www.tec.ac.cr/hoyeneltec/2017/06/29/limonenses-se-comprometen-potenciar-desarrollo-provincia 